\title{
PHYSICAL EXERCISE AND SEX STEROID HORMONES IN BREAST CANCER
}

review paper

( ) University School of Physical Education in Wroclaw

DOI: https://doi.org/10.5114/hm.2021.100006

\section{SÍLVIA ROCHA-RODRIGUES}

School of Sport and Leisure, Polytechnic Institute of Viana do Castelo, Melgaço, Portugal

Research Center in Sports Sciences, Health and Human Development (CIDESD), Vila Real, Portugal

Tumor \& Microenvironment Interactions Group, i3S, Porto, Portugal

\begin{abstract}
Cumulative epidemiological evidence demonstrates that regular physical exercise is one of the most powerful lifestyle strategies used to mitigate the risk of developing breast cancer $(\mathrm{BrC})$ and the disease recurrence. The physical exercise recommendations for $\mathrm{BrC}$ survivors follow the general physical activity guidelines, 150 minutes of moderate-intensity exercise or 75 minutes of vigorous aerobic activity per week. However, to better understand the mechanisms underlying the positive effects of physical exercise is very important to prescribe and implement the most optimal training routine in BrC survivors. As far as we know, sex steroid hormonal response is one of the mechanisms why physical exercise exerts its effects with an additional impact on systemic levels of cancer risk factors. Here, we review the evidence of the physical exercise-mediated alterations in sex steroid hormones and of their ability to prevent or attenuate skeletal toxicities induced by BrC, providing an overview of the effects of physical exercise on the BrC-related underlying mechanisms.
\end{abstract}

Key words: exercise, androgens, oestrogen, female cancer

\section{Introduction}

Breast cancer $(\mathrm{BrC})$ is the leading cancer diagnosis and the second most frequent cause of cancer-related deaths in females [1]. Although with high survival rates, $\mathrm{BrC}$ survivors experience many late and long-term side effects which negatively affect their quality of life after the disease diagnosis and treatments [2-4]. Clinical practice guidelines for $\mathrm{BrC}$ survivors included healthylifestyle counselling related to nutrition, obesity, and physical inactivity [2]. Indeed, physical exercise in oncologic patients has gained a lot of attention, driven by consistent epidemiological evidence that regular physical exercise is associated with lower risk of developing $\mathrm{BrC}$ and its recurrence as compared with inactive lifestyle in cancer survivors [5-8]. Also, additional effects of physical exercise mitigate several adverse events bound with $\mathrm{BrC}$ and its treatments [9-11]. The understanding of the biological mechanisms behind the protective role of physical exercise in $\mathrm{BrC}$ indicates some relevant processes like regulation of the systemic levels of known risk factors, i.e. sex steroid hormones, which have been considered the main candidates as mediators of the physical exercise-dependent protection against $\mathrm{BrC}[12,13]$. In premenopausal women, oestrogens are mainly produced by ovaries, while in postmenopausal women, they are primarily produced in the adipose tissue through aromatization of androgen percursors [14]. After menopause, circulating sex steroid hormones levels and body composition are tightly correlated [15]. Studies consistently reported that elevated circulating sex hormones correlated with increased risk of $\mathrm{BrC}$ in postmenopausal women [16-18]. In this review, we focused on the evidence of the physical exercise-mediated alterations in sex steroid hormones and, additionally, their ability to prevent or attenuate skeletal toxicities induced by $\mathrm{BrC}$, providing an overview of the effects of physical exercise on the BrC-related underlying mechanisms.

Correspondence address: Sílvia Rocha-Rodrigues, Escola Superior Desporto e Lazer, Complexo Desportivo e de Lazer Comendador Rui Solheiro, 4960-320 Melgaço, Viana do Castelo, Portugal, e-mail: silviadarocharodrigues@gmail.com

Received: November 15, 2019

Accepted for publication: September 18, 2020

Citation: Rocha-Rodrigues S. Physical exercise and sex steroid hormones in breast cancer. Hum Mov. 2021;22(2):1-8; doi: https://doi.org/10.5114/hm.2021.100006. 
S. Rocha-Rodrigues, Physical exercise and sex steroid hormones in breast cancer

\section{Ethical approval}

The conducted research is not related to either human or animal use.

\section{The impact of physical exercise on sex steroid hormones}

\section{Premenopausal circulating sex steroid hormones}

The association between endogenous oestrogens and androgens synthesis and BrC risk $[14,19]$ and its biological mechanisms has been described [20]. Oestradiol, a steroid hormone, has been shown to increase breast cell mitosis in vitro, as well as oestrogens and their metabolites to induce deoxyribonucleic acid damage, genetic instability, and cell mutations in vivo $[21,22]$. On the other hand, the role of androgens is more complex as both inhibitory and proliferative effects occur in breast tissue [21], but higher premenopausal androgen levels were likely associated with increased BrC risk [19, 23, 24]. Some studies [14, 19, 22] have shown a tendency for circulating premenopausal steroid hormones to be correlated with BrC risk, but only one of the larger studies [23] demonstrated a strong positive relationship between oestrogen levels and $\mathrm{BrC}$ risk. Furthermore, luteal phase oestradiol levels were suggestively associated with hormone receptor-positive tumours, oestrogen and progesterone receptors or both, but no other strong associations were detected with oestrogens [19]. During the follicular phase, serum levels of oestradiol and the sex hormone binding globulin (SHBG) were strongly correlated with breast density in premenopausal women [14]. It should be noted that one of the major challenges in measuring premenopausal oestrogens is the fluctuation of oestrogen levels across the menstrual cycle and, thus, the potential association between the concentration of circulating sex hormones and $\mathrm{BrC}$ risk needs further studies.

Overweight/obesity is widely recognized as a risk factor for several types of cancer, including $\operatorname{BrC}[25,26]$. Literature supports an inverse association or no association between high body mass index (BMI) and premenopausal hormone receptor-positive $\mathrm{BrC}$ risk [2528 . When abdominal adiposity was considered as a factor, a significant association with both pre- and postmenopausal $\mathrm{BrC}$ risk was detected [29]. The incidence of oestrogen receptor-positive $\mathrm{BrC}$ in obesity supports the role of oestrogen in $\mathrm{BrC}$ carcinogenesis, highlighting the significance of adipose tissue as an endocrine organ [25, 30]. Nevertheless, the relationship between overweight/obesity and $\mathrm{BrC}$ risk is complex and depends on other factors.
Physical exercise has been recognized as one of the strongest strategies to decrease BrC risk by approximately $25-30 \%[2,8]$ in healthy and young women. Although many mechanisms have been suggested for the protective role of physical exercise in the context of $\mathrm{BrC}$, a decrease of circulating levels of steroid hormones is one that has been widely indicated. Randomized controlled trials conducted among healthy women demonstrated a significant decrease in total and free circulating oestradiol concentrations induced by physical activity [13, 31]. A clinical study [32] involving sedentary premenopausal women reported that a 4-cycle intervention of moderate-intensity aerobic exercise combined with caloric restriction resulted in significant decreases in serum oestradiol and urinary estrone-1-glucuronide and pregnanediol glucuronide levels. In contrast, Smith et al. [33] found no alterations in oestradiol, estrone sulfate, testosterone, or SHBG levels after 16 weeks (4 menstrual cycles) of aerobic exercise (150 minutes per week at $65-70 \%$ of maximum age-predicted heart rate) in sedentary, healthy, young and eumenorrheic women. Although studies demonstrated the effect of physical exercise on free oestradiol, a small part of those reporting total oestradiol revealed that the effect of physical exercise was more obvious for free oestradiol than for total oestradiol. The observation that the decreased total oestradiol was related to intervention-induced weight loss, whereas the decrease in free oestradiol was not suggests that the effect of physical exercise on oestradiol is not mediated solely by weight loss but also by the need of oestradiol through increasing levels of binding proteins, as in the case of SHBG levels [34]. As reported by McTiernan et al. [35], 12-week moderateintensity aerobic exercise was able to increase SHBG levels, which likely results in decreased amounts of unbound, active oestrogens and androgens in circulation. Similarly, high-intensity and strength exercise intervention led to a significant decrease in free testosterone but not in total testosterone levels [34].

\section{Postmenopausal circulating sex steroid hormones}

After menopause, adipose tissue is the most important source of oestrogens biosynthesis because the enzyme aromatase converts adrenal androgens to oestrogen [15]. Endogenous sex hormones, particularly oestrogens, have been described to be involved in the initiation, promotion, and progression of tumours [12]. Prolonged exposure to high endogenous hormone levels is considered one of the main risk factors for female $\mathrm{BrC}$, with a relative risk of 2.0 (95\% CI: 1.47-2.71) for 
postmenopausal women with the highest oestradiol concentrations [16]. A reanalysis of studies performed by the Endogenous Hormones and Breast Cancer Collaborative Group concluded that the circulating sex hormone levels in postmenopausal women were strongly associated with several established or suspected risk factors for BrC, including overweight/obesity and low levels of physical exercise [16]. For postmenopausal women, meta-analyses showed positive relationships among overweight, excessive abdominal adiposity, and risk of hormone receptor-positive (oestrogen and progesterone receptor-positive, $\mathrm{ER}+/ \mathrm{PR}+) \mathrm{BrC}[18,36]$. Cross-sectional studies revealed that serum estrone and oestradiol levels were strongly associated with BMI in postmenopausal women [17, 37]. After menopause, the increase in risk of $\mathrm{BrC}$ related with obesity may be explained by the relatively high circulating concentrations of free oestradiol observed in obese postmenopausal women [16]. In contrast to oestrogens, circulating SHBG levels have been consistently reported to be inversely associated with BMI and abdominal adiposity while low SHBG levels result in higher levels of free oestradiol and free testosterone in overweight and obese women [17, 38]. Abdominal adipose tissue accumulation is associated with higher levels of insulin, which inhibits SHBG production [39]. There are some key factors that are augmented in breast tissue of obese women which likely act as stimulators of aromatase, enzyme responsible for the rate-limiting step of oestrogen biosynthesis [1]. The production of these factors is involved in mechanisms for activation of the immune system, linking the immune and hormonal response of obesity [30, 40]. For example, the production and secretion of tumour necrosis factor- $\alpha$ in adipose-infiltrating macrophages rouses the expression of aromatase in adipose fibroblasts [1]. Indeed, increased aromatase levels have been reported in visceral subcutaneous adipose tissue and in adipose tissue of breast of obese postmenopausal women, including inflamed breast adipose tissue of obese women diagnosed with $\mathrm{BrC}$ [41]. This obesity-inflammation-aromatase axis has been proposed as an important mechanism underlying the risk of $\mathrm{BrC}$ in postmenopausal women, increasing oestrogen levels in the breast tissue.

Weight loss interventions have been shown to have beneficial effects on oestradiol, free oestradiol, SHBG, and free testosterone concentrations [6, 42] in $\mathrm{BrC}$ survivors. Accumulative evidence shows that greater amounts of physical activity with $>250$ minutes per week are associated with clinically significant weight loss and weight maintenance after weight loss [5, 43]. A combined aerobic and resistance exercises program has been demonstrated to be more effective to induce favourable outcomes on body composition by improving fat-free mass and loss of fat mass [5, 7], supporting current recommendations for lifestyle interventions for weight loss. In a study by Van Gemert et al. [6], physical exercise-induced fat loss significantly decreased sex steroid hormones and increased SHBG levels, resulting in a less unbound and biologically active oestradiol and testosterone. Other studies found that daily physical activity levels were inversely associated with circulating concentrations of testosterone, oestradiol, and oestrogen and testosterone/SHGB ratio, as well as positively associated with SHBG in postmenopausal women [44, 45]. These observations mainly corresponded with weight loss accompanied by decreased accumulation of abdominal adipose tissue [46-48], the main source of oestrogens after menopause. It may also be mediated by the disruption of the menstrual cycle before menopause [14, 19], especially when physical exercise is associated with low energy density diets. More recently, 6 randomized controlled trials comprised in a meta-analysis have shown that a combined intervention including low calorie intake and physical exercise, with durations ranging from 16 to 52 weeks, had a positive impact on estrone, total and free oestradiol, free testosterone, and SHBG levels in healthy postmenopausal women [49]. Physical exercise without dietary changes was also effective on androstenedione, total oestradiol, and free testosterone in healthy postmenopausal women [49]. Only one study demonstrated that 14 weeks of intensive combined aerobic and resistance exercises (4 hours/week) induced favourable body composition alterations by reducing fat mass and improving fat-free mass (lean mass) compared with a group with similar amount of weight loss induced by following a hypocaloric diet only [6]. Moreover, Rock et al. [50] reported that postmenopausal women who lost more than $5 \%$ of body weight had lower estrone, oestradiol, and bioavailable oestradiol concentrations than women who did not lose weight, suggesting that weight loss promotes favourable changes in systemic biological mediators that have been linked to increased risk for recurrence and mortality in overweight/obese $\mathrm{BrC}$ survivors. Therefore, a decrease of $13 \%$ in oestradiol concentrations has been implied to reduce the risk of $\mathrm{BrC}$ by $8-10 \%$ in overweight/obese postmenopausal women [6]. Moreover, in overweight, inactive postmenopausal women, $6-7 \%$ weight loss induced by 14 weeks of Nordic walking plus a resistance exercise program resulted in improved physical fitness and higher levels on free testosterone [6]. These findings support the knowledge that the loss of fat mass 


\section{Breast cancer risk}

- Luteal phase: oestrogen, progesterone receptors $\uparrow$

- Breast tissue density: follicular phase: oestradiol and SHBG levels $\uparrow$

- Adipose tissue: source of oestrogens biosynthesis via aromatase (postmenopausal)

\section{$\dot{x}$

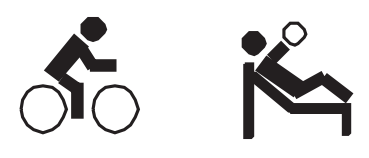

- Combined aerobic and resistance exercise programs improve body composition: $\uparrow$ fat-free mass and $\downarrow$ fat mass

- $\quad$ Physical activity: total and free oestradiol $\downarrow$

- Moderate-intensity aerobic exercise: estrone, $\mathrm{E} 1 \mathrm{G}$, and PDG $\downarrow$

- Resistance exercise: SHBG $\uparrow$ and free testosterone $\downarrow$

\section{SHBG - sex hormone biding globulin, E1G - estrone-1-glucuronide, PDG - pregnanediol glucoronide, $\downarrow$ decrease, $\uparrow$ increase/improve}

Figure 1. Schematic diagram depicting physical exercise interventions modulating sex steroid on BrC

induced by physical exercise instead of diet alone mediates the beneficial effects of physical exercise on sex hormones and help understand the underlying mechanisms connecting physical exercise, sex hormones, and decreased BrC risk (Figure 1).

\section{Circulating sex steroid hormones}

and bone mineral density

Oestrogens play a role in bone growth by inhibiting resorption and increasing the production of hormones involved in bone development, such as 1,25-dihydroxyvitamin $\mathrm{D}$, growth hormone, and insulin-like growth factor-1, in premenopausal women [51, 52]. Nevertheless, no association was demonstrated between serum oestrogen concentrations and bone mineral density (BMD) in premenopausal women during follicular phase [14], while others [53] reported significant inverse relationships between pelvic BMD and urinary 2-hydroxyestrone E1 and 16a-hydroxyestrone E1, two oestradiol metabolites (or genotoxic oestrogens) [54]. Furthermore, an increase of testosterone concentration has been shown to be associated with higher BMD in oestrogen-deficient premenopausal women, and bone loss from the hip was significantly associated with lower androgen concentration [55]. Yong et al. [14] hypothesized that higher testosterone concentrations would be associated with higher BMD owing to the aromatization of testosterone into oestrogens in fat and other tissues [15], but in opposition they observed no relationship between testosterone and lumbar or pelvic BMD, but a significant inverse association between testosterone and head BMD after adjusting for BMI in healthy regularly menstruating women. These findings suggest that as the head is subjected to minimal muscular activity, mechanical stress may provide a more accurate assessment of hormonal, genetic, and dietary influences in the mineral status of the skeleton compared with other, more frequent sites of BMD measurement, such as the lumbar region, hip, and femur.

Cancer and its treatments-induced bone loss are well reported as a long-term problem in $\mathrm{BrC}$ survivors after treatment for cancer malignancies in pre- and postmenopausal women. Indeed, women with history of $\mathrm{BrC}$ had an average of 70 more factures compared with women without $\mathrm{BrC}$ [3]. Chemotherapies are commonly used in the management of $\mathrm{BrC}$; they may promote ovarian dysfunction and accelerate bone loss in premenopausal women and, therefore, increase the risk for clinical fractures. In fact, women diagnosed with $\mathrm{BrC}$ can lose up to $6.8 \%$ of BMD during a 3-year follow-up period and chemotherapy and endocrine therapies are considered the major risk factors [4, 56]. For example, tamoxifen, a selective oestrogen receptor modulator, has both agonist and antagonist effects. In premenopausal women with $\mathrm{BrC}$, tamoxifen can have a negative impact on bone and trials have shown decreased BMD in the treated population. On the other hand, in postmenopausal women, tamoxifen treatment is well known to stabilize or somehow increase BMD 
owing to the oestrogen agonist effects that may counteract postmenopausal bone loss [3]. However, in postmenopausal women, tamoxifen may be followed by aromatase inhibitors, which, in turn, block the activity of this enzyme and oestrogens [4].

Physical exercise is a nonpharmacological approach with the potential to improve or maintain bone health with additional benefits on body weight management, balance, and risk for falling. The American College of Sports Medicine recommends specifically resistance exercises programs 2 or 3 times per week with 2-3 sets to promote bone health during adulthood [57]. To ensure the effectiveness of the resistance exercises, the program should last twice as long (400 days) as bone turnover cycles (200 days). In this line, studies report that physical exercise interventions involving 24 weeks of 150 minutes per week of moderate-intensity aerobic exercise [58], 26 weeks of combined aerobic and resistance training [9], or 1 year of supervised resistance plus impact (jump) exercises [59-61] preserve and improve BMD as well as reduce risk factors for fracture among postmenopausal $\mathrm{BrC}$ survivors. Other investigations have shown improvements in muscle strength and BMD at the hip and spine in BrC survivors who completed 12 weeks [62] or 24 weeks [52] of strength exercises 2 times per week accompanied by bisphosphonate medication, calcium and vitamin D supplementation. Furthermore, circulating bone turnover markers, such as procollagen type $1 \mathrm{~N}$ propeptide (P1NP) and collagen type 1 cross-linked C-telopeptide (CTX), a bone formation and bone resorption marker, respectively, have been recommended for bone health evaluation [9]. Indeed, considerable alterations in bone turnover markers with measurable improvements in BMD were observed after 26 weeks by Almstedt et al. [9] and after 12 months by Shah et al. [63]. Taken together, these findings suggest that long-term ( $>24$ weeks) programs of combined aerobic exercises and strength and impact exercises would be beneficial for improvements in bone health among $\mathrm{BrC}$ survivors. Hereupon, to our best knowledge, the potential role of physical exercise in steroid hormones response preventing or attenuating skeletal toxicities induced by $\mathrm{BrC}$ has been demonstrated.

\section{Conclusions}

Based on compelling data from studies, the current state of knowledge supports physical exercise interventions as part of healthy lifestyle to modulate sex steroid hormones and additionally prevent or attenuate skeletal toxicities induced by $\mathrm{BrC}$ and its treatments.

\section{Acknowledgements}

This work was supported by national funding through the Portuguese Foundation for Science and Technology, I.P., under the UID/DTP/04045/2019 to CIDESD project.

\section{Disclosure statement}

The author does not have any financial interest and did not receive any financial benefit from this research.

\section{Conflict of interest}

The author states no conflict of interest.

\section{References}

1. Bulun SE, Chen D, Moy I, Brooks DC, Zhao H. Aromatase, breast cancer and obesity: a complex interaction. Trends Endocrinol Metab. 2012;23(2):83-89; doi: 10.1016/j.tem.2011.10.003.

2. Friedenreich CM, Cust AE. Physical activity and breast cancer risk: impact of timing, type and dose of activity and population subgroup effects. Br J Sports Med. 2008;42(8):636-647; doi: 10.1136/bjsm.2006.029132.

3. Taxel P, Choksi P, Van Poznak C. The management of osteoporosis in breast cancer survivors. Maturitas. 2012; 73(4):275-279; doi: 10.1016/j.maturitas.2012.08.009.

4. Arimidex, Tamoxifen, Alone or in Combination Trialists' Group; Buzdar A, Howell A, Cuzick J, Wale C, Distler W, et al. Comprehensive side-effect profile of anastrozole and tamoxifen as adjuvant treatment for early-stage breast cancer: long-term safety analysis of the ATAC trial. Lancet Oncol. 2006;7(8):633-643; doi: 10.1016/s1470-2045(06)70767-7.

5. Donnelly JE, Blair SN, Jakicic JM, Manore MM, Rankin JW, Smith BK, et al. American College of Sports Medicine Position Stand. Appropriate physical activity intervention strategies for weight loss and prevention of weight regain for adults. Med Sci Sports Exerc. 2009; 41(2):459-471; doi: 10.1249/MSS.0b013e3181949333.

6. Van Gemert WAM, Schuit AJ, van der Palen J, May AM, Iestra JA, Wittink H, et al. Effect of weight loss, with or without exercise, on body composition and sex hormones in postmenopausal women: the SHAPE-2 trial. Breast Cancer Res. 2015;17(1):120; doi: 10.1186/s13058015-0633-9.

7. Campbell WW, Haub MD, Wolfe RR, Ferrando AA, Sullivan DH, Apolzan JW, et al. Resistance training preserves fat-free mass without impacting changes in protein metabolism after weight loss in older women. Obesity. 2009;17(7):1332-1339; doi: 10.1038/oby.2009.2.

8. Adraskela K, Veisaki E, Koutsilieris M, Philippou A. Physical exercise positively influences breast cancer evolution. Clin Breast Cancer. 2017;17(6):408-417; doi: 10.1016/j.clbc.2017.05.003.

9. Almstedt HC, Grote S, Korte JR, Beaudion SP, Shoepe TC, Strand S, et al. Combined aerobic and resistance training improves bone health of female cancer survivors. 
Bone Rep. 2016;5:274-279; doi: 10.1016/j.bonr.2016. 09.003.

10. Dalla Via J, Daly RM, Fraser SF. The effect of exercise on bone mineral density in adult cancer survivors: a systematic review and meta-analysis. Osteoporos Int. 2018; 29(2):287-303; doi: 10.1007/s00198-017-4237-3.

11. Kim TH, Chang JS, Kong ID. Effects of exercise training on physical fitness and biomarker levels in breast cancer survivors. J Lifestyle Med. 2017;7(2):55-62; doi: 10.15280/jlm.2017.7.2.55.

12. Pike MC, Krailo MD, Henderson BE, Casagrande JT, Hoel DG. 'Hormonal' risk factors, 'breast tissue age' and the age-incidence of breast cancer. Nature. 1983; 303(5920):767-770; doi: 10.1038/303767a0.

13. Verkasalo PK, Thomas HV, Appleby PN, Davey GK, Key TJ. Circulating levels of sex hormones and their relation to risk factors for breast cancer: a cross-sectional study in 1092 pre- and postmenopausal women (United Kingdom). Cancer Causes Control. 2001;12(1): 47-59; doi: 10.1023/a:1008929714862.

14. Yong M, Atkinson C, Newton KM, Aiello Bowles EJ, Stanczyk FZ, Westerlind KC, et al. Associations between endogenous sex hormone levels and mammographic and bone densities in premenopausal women. Cancer Causes Control. 2009;20(7):1039-1053; doi: 10.1007/ s10552-009-9321-3.

15. Liedtke S, Schmidt ME, Vrieling A, Lukanova A, Becker S, Kaaks R, et al. Postmenopausal sex hormones in relation to body fat distribution. Obesity. 2012;20(5): 1088-1095; doi: 10.1038/oby.2011.383.

16. Endogenous Hormones and Breast Cancer Collaborative Group; Key TJ, Appleby PN, Reeves GK, Roddam AW, Helzlsouer KJ, et al. Circulating sex hormones and breast cancer risk factors in postmenopausal women: reanalysis of 13 studies. Br J Cancer. 2011;105(5):709722; doi: 10.1038/bjc.2011.254.

17. Lukanova A, Lundin E, Zeleniuch-Jacquotte A, Muti P, Mure A, Rinaldi S, et al. Body mass index, circulating levels of sex-steroid hormones, IGF-I and IGF-binding protein-3: a cross-sectional study in healthy women. Eur J Endocrinol. 2004;150(2):161-171; doi: 10.1530/ eje.0.1500161.

18. Liu K, Zhang W, Dai Z, Wang M, Tian T, Liu X, et al. Association between body mass index and breast cancer risk: evidence based on a dose-response meta-analysis. Cancer Manag Res. 2018;10:143-151; doi: 10.2147/ cmar.s144619.

19. Fortner RT, Eliassen AH, Spiegelman D, Willett WC, Barbieri RL, Hankinson SE. Premenopausal endogenous steroid hormones and breast cancer risk: results from the Nurses' Health Study II. Breast Cancer Res. 2013;15(2):R19; doi: 10.1186/bcr3394.

20. Birrell SN, Bentel JM, Hickey TE, Ricciardelli C, Weger MA, Horsfall DJ, et al. Androgens induce divergent proliferative responses in human breast cancer cell lines. J Steroid Biochem Mol Biol. 1995;52(5):459_ 467; doi: 10.1016/0960-0760(95)00005-k.
21. Peters AA, Ingman WV, Tilley WD, Butler LM. Differential effects of exogenous androgen and an androgen receptor antagonist in the peri- and postpubertal murine mammary gland. Endocrinology. 2011;152(10): 3728-3737; doi: 10.1210/en.2011-1133.

22. Walker K, Bratton DJ, Frost C. Premenopausal endogenous oestrogen levels and breast cancer risk: a metaanalysis. Br J Cancer. 2011;105(9):1451-1457; doi: 10.1038/bjc.2011.358.

23. Eliassen AH, Missmer SA, Tworoger SS, Spiegelman D, Barbieri RL, Dowsett M, et al. Endogenous steroid hormone concentrations and risk of breast cancer among premenopausal women. J Natl Cancer Inst. 2006;98(19):1406-1415; doi: 10.1093/jnci/djj376.

24. Zeleniuch-Jacquotte A, Afanasyeva Y, Kaaks R, Rinaldi S, Scarmo S, Liu M, et al. Premenopausal serum androgens and breast cancer risk: a nested case-control study. Breast Cancer Res. 2012;14(1):R32; doi: 10.1186/bcr3117.

25. Lauby-Secretan B, Scoccianti C, Loomis D, Grosse Y, Bianchini F, Straif K, et al. Body fatness and cancer viewpoint of the IARC Working Group. N Engl J Med. 2016;375(8):794-798; doi: 10.1056/NEJMsr1606602.

26. Picon-Ruiz M, Morata-Tarifa C, Valle-Goffin JJ, Friedman ER, Slingerland JM. Obesity and adverse breast cancer risk and outcome: mechanistic insights and strategies for intervention. CA Cancer J Clin. 2017;67(5): 378-397; doi: 10.3322/caac.21405.

27. White AJ, Nichols HB, Bradshaw PT, Sandler DP. Overall and central adiposity and breast cancer risk in the Sister Study. Cancer. 2015;121(20):3700-3708; doi: 10.1002/cncr.29552.

28. Kawai M, Malone KE, Tang MTC, Li CI. Height, body mass index (BMI), BMI change, and the risk of estrogen receptor-positive, HER2-positive, and triple-negative breast cancer among women ages 20 to 44 years. Cancer. 2014;120(10):1548-1556; doi: 10.1002/cncr.28601.

29. Connolly BS, Barnett C, Vogt KN, Li T, Stone J, Boyd NF. A meta-analysis of published literature on waist-to-hip ratio and risk of breast cancer. Nutr Cancer. 2002; 44(2):127-138; doi: 10.1207/s15327914nc4402_02.

30. Rocha-Rodrigues S, Gonçalves IO, Beleza J, Ascensão A, Magalhães J. Physical exercise mitigates high-fat diet-induced adiposopathy and related endocrine alterations in an animal model of obesity. J Physiol Biochem. 2018;74(2):235-246; doi: 10.1007/s13105-018-0609-1.

31. Tworoger SS, Missmer SA, Eliassen AH, Barbieri RL, Dowsett M, Hankinson SE. Physical activity and inactivity in relation to sex hormone, prolactin, and insulinlike growth factor concentrations in premenopausal women - exercise and premenopausal hormones. Cancer Causes Control. 2007;18(7):743-752; doi: 10.1007/ s10552-007-9017-5.

32. Williams NI, Reed JL, Leidy HJ, Legro RS, De Souza MJ. Estrogen and progesterone exposure is reduced in response to energy deficiency in women aged $25-40$ years. Hum Reprod. 2010;25(9):2328-2339; doi: 10.1093/ humrep/deq172. 
33. Smith AJ, Phipps WR, Arikawa AY, O’Dougherty M, Kaufman B, Thomas W, et al. Effects of aerobic exercise on premenopausal sex hormone levels: results of the WISER study, a randomized clinical trial in healthy, sedentary, eumenorrheic women. Cancer Epidemiol Biomarkers Prev. 2011;20(6):1098-1106; doi: 10.1158/ 1055-9965.epi-10-1219.

34. Ennour-Idrissi K, Maunsell E, Diorio C. Effect of physical activity on sex hormones in women: a systematic review and meta-analysis of randomized controlled trials. Breast Cancer Res. 2015;17(1):139; doi: 10.1186/ s13058-015-0647-3.

35. McTiernan A, Tworoger SS, Ulrich CM, Yasui Y, Irwin ML, Rajan KB, et al. Effect of exercise on serum estrogens in postmenopausal women: a 12-month randomized clinical trial. Cancer Res. 2004;64(8):29232928; doi: 10.1158/0008-5472.can-03-3393.

36. Agurs-Collins T, Ross SA, Dunn BK. The many faces of obesity and its influence on breast cancer risk. Front Oncol. 2019;9:765; doi: 10.3389/fonc.2019.00765.

37. Rinaldi S, Key TJ, Peeters PHM, Lahmann PH, Lukanova $\mathrm{A}$, Dossus L, et al. Anthropometric measures, endogenous sex steroids and breast cancer risk in postmenopausal women: a study within the EPIC cohort. Int J Cancer. 2006;118(11):2832-2839; doi: 10.1002/ijc.21730.

38. Hajamor S, Després J-P, Couillard C, Lemieux S, Tremblay A, Prud'homme D, et al. Relationship between sex hormone-binding globulin levels and features of themetabolic syndrome. Metabolism. 2003;52(6):724730; doi: 10.1016/s0026-0495(03)00066-0.

39. Daka B, Rosen T, Jansson PA, Råstam L, Larsson CA, Lindblad U. Inverse association between serum insulin and sex hormone-binding globulin in a population survey in Sweden. Endocr Connect. 2012;2(1):18-22; doi: 10.1530/EC-12-0057.

40. Rocha-Rodrigues S, Rodríguez A, Gonçalves IO, Moreira A, Maciel E, Santos S, et al. Impact of physical exercise on visceral adipose tissue fatty acid profile and inflammation in response to a high-fat diet regimen. Int J Biochem Cell Biol. 2017;87:114-124; doi: 10.1016/j. biocel.2017.04.008.

41. Morris PG, Hudis CA, Giri D, Morrow M, Falcone DJ, Zhou XK, et al. Inflammation and increased aromatase expression occur in the breast tissue of obese women with breast cancer. Cancer Prev Res. 2011;4(7):10211029; doi: 10.1158/1940-6207.capr-11-0110.

42. Foster-Schubert KE, Alfano CM, Duggan CR, Xiao L, Campbell KL, Kong A, et al. Effect of diet and exercise, alone or combined, on weight and body composition in overweight-to-obese postmenopausal women. Obesity. 2012;20(8):1628-1638; doi: 10.1038/oby.2011.76.

43. Murawska-Cialowicz E, Zuwala-Jagiello J. Effects of training versus short exercise session on homocysteine levels in women with different body mass. Hum Mov. 2018;19(2):18-30; doi: 10.5114/hm.2018.74634.

44. Chan MF, Dowsett M, Folkerd E, Bingham S, Wareham N, Luben R, et al. Usual physical activity and en- dogenous sex hormones in postmenopausal women: the European prospective investigation into cancer Norfolk population study. Cancer Epidemiol Biomarkers Prev. 2007;16(5):900-905; doi: 10.1158/1055-9965. epi-06-0745.

45. Bertone-Johnson ER, Tworoger SS, Hankinson SE. Recreational physical activity and steroid hormone levels in postmenopausal women. Am J Epidemiol. 2009;170(9): 1095-1104; doi: 10.1093/aje/kwp254.

46. McTiernan A, Wu L, Chen C, Chlebowski R, MossavarRahmani Y, Modugno F, et al. Relation of BMI and physical activity to sex hormones in postmenopausal women. Obesity. 2006;14(9):1662-1677; doi: 10.1038/ oby.2006.191.

47. Rocha-Rodrigues S, Rodríguez A, Becerril S, Ramírez B, Gonçalves IO, Beleza J, et al. Physical exercise remodels visceral adipose tissue and mitochondrial lipid metabolism in rats fed a high-fat diet. Clin Exp Pharmacol Physiol. 2017;44(3):386-394; doi: 10.1111/14401681.12706.

48. Kantyka J, Herman D, Roczniok R, Kuba L. Effects of aqua aerobics on body composition, body mass, lipid profile, and blood count in middle-aged sedentary women. Hum Mov. 2015;16(1):9-14; doi: 10.1515/humo2015-0020.

49. De Roon M, May AM, McTiernan A, Scholten RJPM, Peeters PHM, Friedenreich CM, et al. Effect of exercise and/or reduced calorie dietary interventions on breast cancer-related endogenous sex hormones in healthy postmenopausal women. Breast Cancer Res. 2018;20(1): 81; doi: 10.1186/s13058-018-1009-8.

50. Rock CL, Pande C, Flatt SW, Ying C, Pakiz B, Parker BA, et al. Favorable changes in serum estrogens and other biologic factors after weight loss in breast cancer survivors who are overweight or obese. Clin Breast Cancer. 2013;13(3):188-195; doi: 10.1016/j.clbc.2012.12.002.

51. Pacifici R. Cytokines, estrogen, and postmenopausal osteoporosis - the second decade. Endocrinology. 1998; 139(6):2659-2661; doi: 10.1210/endo.139.6.6087.

52. Waltman NL, Twiss JJ, Ott CD, Gross GJ, Lindsey AM, Moore TE, et al. The effect of weight training on bone mineral density and bone turnover in postmenopausal breast cancer survivors with bone loss: a 24-month randomized controlled trial. Osteoporos Int. 2010; 21(8):1361-1369; doi: 10.1007/s00198-009-1083-y.

53. Sowers MR, Finkelstein JS, Ettinger B, Bondarenko I, Neer RM, Cauley JA, et al. The association of endogenous hormone concentrations and bone mineral density measures in pre- and perimenopausal women of four ethnic groups: SWAN. Osteoporos Int. 2003;14(1):4452; doi: 10.1007/s00198-002-1307-x.

54. Mauras N, Santen RJ, Colón-Otero G, Hossain J, Wang Q, Mesaros C, et al. Estrogens and their genotoxic metabolites are increased in obese prepubertal girls. J Clin Endocrinol Metab. 2015;100(6):2322-2328; doi: 10.1210/jc.2015-1495. 


\section{HUMAN MOVEMENT}

S. Rocha-Rodrigues, Physical exercise and sex steroid hormones in breast cancer

55. Guthrie JR, Ebeling PR, Hopper JL, Barrett-Connor E, Dennerstein L, Dudley EC, et al. A prospective study of bone loss in menopausal Australian-born women. Osteoporos Int. 1998;8(3):282-290; doi: 10.1007/s0019800 50066.

56. Kim SH, Cho YU, Kim SJ, Han MS. Changes in bone mineral density in women with breast cancer: a prospective cohort study. Cancer Nurs. 2019;42(2):164-172; doi: 10.1097/ncc.0000000000000586.

57. American College of Sports Medicine. American College of Sports Medicine position stand. Progression models in resistance training for healthy adults. Med Sci Sports Exerc. 2009;41(3):687-708; doi: 10.1249/MSS. 0b013e3181915670.

58. Irwin ML, Alvarez-Reeves M, Cadmus L, Mierzejewski E, Mayne ST, Yu H, et al. Exercise improves body fat, lean mass, and bone mass in breast cancer survivors. Obesity. 2009;17(8):1534-1541; doi: 10.1038/oby.2009.18.

59. Winters-Stone KM, Dobek J, Nail L, Bennett JA, Leo MC, Naik A, et al. Strength training stops bone loss and builds muscle in postmenopausal breast cancer survivors: a randomized, controlled trial. Breast Cancer Res Treat. 2011;127(2):447-456; doi: 10.1007/s10549-011-1444-z.

60. Winters-Stone KM, Dobek J, Nail LM, Bennett JA, Leo MC, Torgrimson-Ojerio B, et al. Impact + resistance training improves bone health and body composition in prematurely menopausal breast cancer survivors: a randomized controlled trial. Osteoporos Int. 2013; 24(5):1637-1646; doi: 10.1007/s00198-012-2143-2.

61. Dobek J, Winters-Stone KM, Bennett JA, Nail L. Musculoskeletal changes after 1 year of exercise in older breast cancer survivors. J Cancer Surviv. 2014;8(2): 304-311; doi: 10.1007/s11764-013-0313-7.

62. Waltman NL, Twiss JJ, Ott CD, Gross GJ, Lindsey AM, Moore TE, et al. Testing an intervention for preventing osteoporosis in postmenopausal breast cancer survivors. J Nurs Scholarsh. 2003;35(4):333-338; doi: 10.1111/ j.1547-5069.2003.00333.x.

63. Shah K, Armamento-Villareal R, Parimi N, Chode S, Sinacore DR, Hilton TN, et al. Exercise training in obese older adults prevents increase in bone turnover and attenuates decrease in hip bone mineral density induced by weight loss despite decline in bone-active hormones. J Bone Miner Res. 2011;26(12):2851-2859; doi: 10.1002/jbmr.475. 